\title{
Feasibility of Implementing Community Partnerships to Provide Diabetes Prevention Services to Youth
}

Julie M. Pike, RD, CDE, is a dietitian and diabetes educator with the Youth Diabetes Prevention Clinic and the Get a Move On program at Indiana University Health and Indiana University School of Medicine in Indianapolis, Indiana.julpike@iu.edu

Lisa Yazel-Smith, MS, MCHES, CCRP, is a Master Certified Health Education Specialist and a project manager at Indiana University School of Medicine. smithlg@iupui.edu

Kathryn M. Haberlin, MPH, CHES, is a health educator with the Youth Diabetes Prevention Clinic and the Get a Move On program at Indiana University Health and Indiana University School of Medicine in Indianapolis, Indiana.khaberli@iupui.edu

Tamara S. Hannon, MD, is a Professor of Pediatrics at Indiana University School of Medicine and the medical director of the Youth Diabetes Prevention Clinic at Indiana University Health in Indianapolis, Indiana. tshannon@iu.edu

Address correspondence to: Julie M. Pike RD, CDE, Department of Pediatric and Adolescent Comparative Effectiveness Research, Indiana University School of Medicine, 410 West $10^{\text {th }} \mathrm{St}$, Indianapolis, IN 46202. Phone: 317-688-5065. Fax: 317-321-0128. Email:julpike@iu.edu.

\section{Acknowledgements}

Julie Pike developed curriculum, facilitated the group sessions and drafted the manuscript. Lisa Smith and Kathryn Haberlin made substantial contributions to the manuscript. Katie Haberlin developed curriculum and facilitated group sessions. Dr. Tamara Hannon revised the manuscript and gave final approval. 


\begin{abstract}
Type 2 diabetes (T2D) in youth has increased as a result of the obesity epidemic. Diabetes prevention programming is needed for youth, at risk for T2D, and their families. However, there is a lack of diabetes prevention services for this population.
\end{abstract}

There is evidence for the benefit of lifestyle modification for decreasing diabetes risk, however there are barriers for youth to access these services in a traditional clinical setting. Our Youth Diabetes Prevention Clinic (YDPC) created partnerships within the community to increase access to diabetes prevention services for at risk youth.

YDPC personnel approached community organizations who had the expertise and capacity to partner in needed areas. These partnerships allowed for the development and facilitation of a community-based diabetes prevention group. Youth and their families participated in a 12 week diabetes prevention group. We measured attendance and participant satisfaction with the program.

Families attended an average of 5.1 sessions from January to October 2016. Participant satisfaction was collected five times. Physical activity was rated as "awesome" or "good" by $88 \%$ of the respondents. The nutrition activities were rated as "awesome" or "good" by $97 \%$ of respondents.

Physicians and families express a desire for diabetes prevention services, however barriers make it difficult for families to fully participate. Creating partnerships within the community allows for increased access to diabetes prevention services for high-risk, underserved families.

Key words: diabetes prevention; adolescents; community-based, community partnership 


\section{Introduction}

The obesity epidemic has led to an increase in type 2 diabetes (T2D) in adolescents. From 2001 to 2009 , T2D in adolescents increased approximately 30 percent [1], and it is projected to increase four-fold over the next 40 years [2]. This is especially concerning as T2D in adolescents is associated with poor health outcomes and increased health care costs. The Treatment of Diabetes in Adolescents and Youth study demonstrated the difficulty of achieving glycemic control with traditional means and the premature development of serious comorbidities in youthonset T2D [3]. These findings underline the importance of diabetes prevention.

The beneficial effects of modest weight loss and increased physical activity on diabetes prevention in adults are clearly demonstrated in the National Diabetes Prevention Program (DPP) [4]. However, few studies discuss successful interventions aimed at youth. Family-based interventions have shown sustained beneficial effects on body composition and insulin sensitivity in overweight children [5]. Nevertheless, lifestyle intervention programs for children and adolescents face unique challenges due to the effects parents and other family members have on behavior modification [6].

Despite the need, diabetes prevention services and programs geared towards youth and their families are scarce. In effort to address challenges to traditional clinic-based programs and to provide services to a high-risk population, the Youth Diabetes Prevention Clinic (YDPC) partnered with a variety of organizations to create a community-based, family-centered diabetes prevention group. This group, Get a Move On (GAMO), exemplifies the value of partnerships between health care, a community organization, academia and the private sector to provide diabetes prevention services. Here, we describe the development and feasibility of this program, as well as, the community partnerships that made it possible. 


\section{Methods}

YDPC, an IU Health pediatric specialty clinic, provides medical treatment and diabetes prevention education for youth, ages 10-21, who are at high risk for T2D. YDPC provides screening for diabetes, nutrition consultation, health coaching, clinical and laboratory assessment, and treatment. YDPC identified a need, not only to provide diabetes screening and prevention education in the clinical setting, but to offer real life experiences implementing those messages in a supportive group environment. It was also apparent that families required diabetes screening and prevention services at a convenient location, at a suitable time and with a flexible structure to optimize participation. Lastly, the ongoing group meetings needed to be appealing and engaging to youth and their families. In short, it needed to be useful, beneficial, and fun.

In order to achieve these aims, YDPC approached potential community partner organizations. YDPC sought out organizations who 1) had the expertise and capacity to partner in needed areas 2) were already providing services to the target population, and 3) were trusted members of the community. We identified the following partners: The John Boner Fitness and Learning Center at the Chase Legacy Building (Boner Center), Indiana University-Purdue University Physically Active Residential Communities and Schools (PARCS) program and The Patachou Foundation (TPF).

The John Boner Center, a trusted community resource in Indianapolis, is a social service organization with the mission to improve the quality of life in their neighborhood. The Boner Center offers a full-service fitness facility, educational greenhouse and garden, instructional kitchen and classroom space. Partnering with the Boner Center provided YDPC patients with a convenient location, and at the same time, increased access to diabetes prevention programming 
for families in the neighborhood. Thus, meeting our needs for location while aligning with the Boner Center's mission to improve quality of life in their neighborhood.

The PARCS program at Indiana University-Purdue University Indianapolis (IUPUI) provides physical education students to staff the fitness facility at the Boner Center. We approached faculty at IUPUI about partnering to provide their students with opportunities to lead physical fitness activities and games for youth. This partnership gave PARCS students hands-on learning experiences and helped us to facilitate the physical activity portion of the group.

The Patachou Foundation (TPF) feeds wholesome meals to food-insecure children in the community. According to the Center for Disease Control online food mapping tool, the Near Eastside Neighborhood of Indianapolis where GAMO was offered, meets the criteria of a food desert. Partnering with TPF increased their access to youth and their families in a food insecure neighborhood while allowing us to serve a healthy dinner for GAMO participants every week. This shared meal created opportunities for families to try new foods and healthy recipes. TPF was also an invaluable partner in the creation of a fun, hands-on curriculum. YDPC staff worked with culinary experts at TPF to translate evidence-based nutrition messages into cooking activities and recipes.

\section{Program Development}

GAMO is based on the Social Cognitive Theory (SCT) [6]. This health behavior theory has been widely used in the development of public health and health promotion interventions in youth. The successful application of SCT in a community-based intervention for youth has been previously published [7].

Table 1 shows the relationship between the SCT concepts and GAMO intervention strategies. 
GAMO met weekly, for 2 hours, to provide families with opportunities for consistent physical activity, nutrition-related education and social support. Youth and their families engaged in physical activity during the first hour. The second hour consisted of 20 to 30 minutes of nutrition education and a shared meal. Sessions were facilitated by a registered dietitian and a health education specialist. Youth and their families were incentivized to set weekly goals, track progress of goals and keep food and activity records.

Nutrition and physical activity messages were adapted from the Expert Committee Recommendations Regarding the Prevention, Assessment and Treatment of Child and Adolescent Overweight and Obesity [8]. These recommendations include limiting sugarsweetened beverages, encouraging fruits and vegetables, eating breakfast daily, limiting eating out, limiting portion size, encouraging family meals and limiting television and screen time. In addition, they recommend limiting energy-dense foods and eating a diet with balanced micronutrients. They also promote moderate to vigorous physical activity for at least 60 minutes a day. Nutrition and physical activity messages needed to be explicit, achievable and targeted towards behaviors that would have the most impact. It was also important to develop content for diverse families with varying degrees of diabetes risk and motivation to make lifestyle changes.

Based upon these target behaviors, the curriculum utilized a 12-week cycle of six nutrition messages and one physical activity message: 1) Choose water. Eliminate sugary drinks. 2) Choose fruits and vegetables at meals and snacks. 3) Eat breakfast every day. 4) Eat healthy snacks. 5) Practice portion control. 6) Eat at home. 7) Be physically active every day. Choose My Plate was used to reinforce the concept of nutritionally balanced meals and portion control. The concept of family meals was reinforced by the shared meals at GAMO. Corresponding hands-on activities were added to the curriculum to reinforce the messages. 
Table 2 outlines the nutrition messages and corresponding activities.

Additionally, physical activity messaging was delivered by the PARCS students in the form of age-appropriate physical activities. No structured curriculum for physical activity was written. Instead, the focus was on developing an inclusive group environment where youth could have fun moving for 45-60 minutes. At the end of the physical activity, participants were asked to share what they liked about the activity and how they felt after engaging in activity. This participant feedback reinforced the messages that physical activity is fun and feels good.

\section{Population}

Youth and their families were recruited for the pilot study from YDPC and pediatric primary care providers located in the Indianapolis metropolitan area. We also met with staff at the Boner Center, as well as, churches and schools in the Near Eastside neighborhood to share information about GAMO and recruit families in the neighborhood. Requirements for group participation included the following criteria: 1) $\geq 10$ years of age 2) BMI of $\geq 85^{\text {th }}$ percentile for gender and age and 3) a parent or guardian who was willing to attend the group.

Table 3 shows the youth participant characteristics.

Families seen in YDPC received information about GAMO and were offered the opportunity to enroll at the time of their YDPC appointment. Families who did not enroll but expressed interest in the group received a weekly phone call for four weeks and a follow up letter providing information about GAMO. Other pediatric practices and community organizations were given information about GAMO and referral instructions. These families were contacted within one week of receiving the referral. Families received weekly phone calls for four weeks and a letter providing information about GAMO. Referring providers also received letters indicating the 
outcome of their referral. All families were invited to enroll in GAMO at any time and/or restart the group when their schedule allowed.

This study was approved by the Indiana University Review Board.

\section{Results}

From January 2016 to October 2016, GAMO received 120 referrals from YDPC and other pediatric primary care practices. We did not receive referrals from community organizations. Twenty-nine families or $24 \%$ of families referred attended at least one GAMO session.

Table 4 Shows referral sources and the number of families who attended at least 1 session.

Families attended an average of 5.1 sessions from January to October 2016. In the first six months of the program, families attended an average of three sessions. Average weekly attendance through June 2016 was 10 participants. In the latter four months of the program, families attended an average of six sessions. Average attendance from July to October 2016 was 18 participants. Seven families attended more than 12 sessions. Families who attended more than 12 sessions averaged 20 sessions from January to October 2016.

Participant satisfaction was collected five times during the pilot study. Participant satisfaction was measured on a five point Likert scale. Categories were awesome, good, not good or bad, bad and terrible. Physical activity was rated as awesome or good by $88 \%$ of the respondents. The nutrition activities were rated as awesome or good by $97 \%$ of respondents.

All GAMO participants were referred by either YDPC or a pediatric primary care provider.

Clinic referral sheets indicated that BMI had been assessed to meet the inclusion criteria of $\geq 85^{\text {th }}$ 
percentile for gender and age. We did not measure BMI at the end of 12 weeks as this study focused on feasibility. BMI will be a future measurement of program outcomes.

\section{Discussion}

We have shown that a community-based diabetes prevention group for youth and their families is feasible and positively received by participants. We found that many families want this service but struggle to take advantage of it due to difficulties with transportation, work schedules and other competing priorities. Families that did attend regularly continued to engage in the program past the 12 week curriculum cycle. Satisfaction surveys indicate that families enjoy the physical activity, cooking sessions and social support provided by the group setting.

The Bright Bodies Healthy Lifestyle Program (BB) demonstrated the positive effects of intensive lifestyle intervention on improvements in body composition and insulin sensitivity [5]. BB participants received nutrition education, behavior modification and twice weekly physical activity sessions for six months. GAMO also offered nutrition education and physical activity in a community setting, however, this program differs in its approach by bringing together diverse community organizations with unique resources to meet the needs of youth, at high risk for T2D, and their families.

The DPP, which provides clear evidence of the beneficial effects of lifestyle change on diabetes prevention, has been effectively translated into a variety of community settings [9-15]. However, the DPP has not yet been translated into a family-focused intervention and typically relies on one organization for program facilitation.

The acceptability and feasibility of this pilot study demonstrates the potential for community organizations to combine resources for diabetes prevention services in a way that meets the 
needs of families while aligning with each stakeholder's mission. This may allow for broader implementation of prevention services in communities where traditional clinic-based services are not easily accessible.

\section{Limitations}

There are limitations to our pilot program. First, GAMO relies on donations from partner organizations and resources from a large health care system. Program sustainability is essential to continue to offer services to families in the community. Ideally, health insurers would reimburse preventive services for youth. Second, we found that community partners and organizations in the neighborhood did not refer families to the program. This may be due to the organizations being unfamiliar or uncomfortable referring families to a healthy lifestyle program. This may have also been due to the newness of GAMO in the neighborhood. Outcomes were shared with partner organizations at the completion of the pilot, however, more formal measurements of benefits to partner organizations should be measured and quantified in the future. Finally, the GAMO curriculum focused primarily on family behavior change and behavioral capability but did not address environmental influences that are in the outer setting of GAMO, such as at school and access to healthy food choices in the neighborhood. We do not have BMI outcomes for this pilot study. We now have funding to obtain this data, as well as, measure changes in food choices and level of physical activity.

\section{Conclusions}

$\mathrm{T} 2 \mathrm{D}$ in youth is a growing concern, and there is evidence that modifying eating and physical activity behaviors can be an effective way to intervene in the trajectory of T2D in youth. However, there is a lack of appropriate lifestyle modification support for youth. We have shown 
Diabetes Prevention in Youth

the development and feasibility of community health partnerships toward the goal of improving diabetes prevention efforts in high-risk communities. 
Table 1 Social Cognitive Theory (SCT) Constructs Apparent in GAMO Intervention

\begin{tabular}{|c|c|}
\hline SCT Construct & GAMO Specific Intervention Strategy \\
\hline Self-efficacy & $\begin{array}{l}\text { - } \quad \text { Participation in weekly physical activity sessions. } \\
\text { - } \quad \text { Preparation of healthy meals and snacks. } \\
\text { - } \quad \text { Taste testing fruits, vegetables and new recipes. } \\
\text { - } \quad \text { Practicing portion control at shared meals. } \\
\text { - } \quad \text { Engaging in meal planning activities. }\end{array}$ \\
\hline Collective-efficacy & $\begin{array}{l}\text { - Group physical activity sessions. } \\
\text { - Completion of } 5 \mathrm{~K} \text { race as a group. } \\
\text { - } \quad \text { Cooking together to prepare a healthy meal. } \\
\text { - Combining cooking skills and recipes to make a } \\
\text { healthy holiday celebration. }\end{array}$ \\
\hline Knowledge & $\begin{array}{l}\text { - Using the nutrition label to evaluate foods and } \\
\text { beverages. } \\
\text { - Measuring serving size and comparing it to typical } \\
\text { portions. } \\
\text { - Measuring the amount of added sugar in typical foods } \\
\text { and drinks and comparing amounts to recommended } \\
\text { daily limits. } \\
\text { Instruction on meal planning and healthy cooking } \\
\text { techniques. }\end{array}$ \\
\hline Observational learning & $\begin{array}{l}\text { - Group sharing of goals and goal progress. } \\
\text { - Peer to peer instruction during nutrition and cooking } \\
\text { activities. }\end{array}$ \\
\hline Social support & $\begin{array}{l}\text { - Opportunity for participants to share goal progress and } \\
\text { support each other. }\end{array}$ \\
\hline Barriers and opportunities & $\begin{array}{l}\text { - Provided opportunities to try new behaviors in a } \\
\text { supportive group environment. }\end{array}$ \\
\hline Intentions & - Weekly goal setting, tracking and feedback. \\
\hline
\end{tabular}


Diabetes Prevention in Youth

\begin{tabular}{|l|ll}
\hline Reinforcement & $\bullet$ Monthly drawings for self-monitoring behaviors.
\end{tabular}


Table 2 Nutrition Messages and Corresponding Learning Activities

\begin{tabular}{|c|c|}
\hline Nutrition Message & Learning Activity \\
\hline Choose water. Eliminate sugary drinks. & $\begin{array}{l}\text { Measure the amount of sugar in a variety of } \\
\text { beverages. Compare amounts to } \\
\text { recommended daily limits. }\end{array}$ \\
\hline Choose water. Eliminate sugary drinks. & $\begin{array}{l}\text { Make a fruit-infused water and taste test a } \\
\text { variety of sugar free beverages. }\end{array}$ \\
\hline $\begin{array}{l}\text { Choose fruits and vegetables at meals and } \\
\text { snacks. }\end{array}$ & $\begin{array}{l}\text { Taste test a variety fruits and vegetables using } \\
\text { different cooking methods. }\end{array}$ \\
\hline $\begin{array}{l}\text { Choose fruits and vegetables at meals and } \\
\text { snacks. }\end{array}$ & Use fruits and vegetables to make smoothies. \\
\hline Eat breakfast every day. & $\begin{array}{l}\text { Use food labels to evaluate different breakfast } \\
\text { foods. Reinforce messages of fruits, } \\
\text { vegetables and added sugar. Introduce whole } \\
\text { grains. }\end{array}$ \\
\hline Eat breakfast every day. & $\begin{array}{l}\text { Make a healthy breakfast. Taste breakfast } \\
\text { ideas with fruits, vegetables and whole grains. }\end{array}$ \\
\hline Choose healthy snacks. & $\begin{array}{l}\text { Use labels to evaluate common snacks. } \\
\text { Reinforce previous nutrition messages of } \\
\text { fruits, vegetables, whole grains. Introduce } \\
\text { portion control. }\end{array}$ \\
\hline Choose healthy snacks. & $\begin{array}{l}\text { Prepare a healthy snack that includes fruits } \\
\text { and vegetables. }\end{array}$ \\
\hline Practice portion control. & $\begin{array}{l}\text { Label reading to determine serving sizes of a } \\
\text { variety of foods. Compare serving size to } \\
\text { typical portions. }\end{array}$ \\
\hline Practice portion control. & $\begin{array}{l}\text { Make a stir fry meal and practice "plate } \\
\text { method" for portion control. }\end{array}$ \\
\hline Eat at home. & Meal planning and budgeting activity. \\
\hline Eat at home. & Cook once, eat twice cooking activity. \\
\hline
\end{tabular}


Diabetes Prevention in Youth

Table 3: GAMO Youth Participant Characteristics

\begin{tabular}{|l|l|}
\hline Average age & 12.2 \\
\hline Male & $32(40.5 \%)$ \\
\hline Female & $47(59.5 \%)$ \\
\hline
\end{tabular}


Diabetes Prevention in Youth

Table 4: GAMO Enrollment

\begin{tabular}{|l|l|l|}
\hline Referral source & Number of referrals & $\begin{array}{l}\text { Number of referrals who } \\
\text { attended at least } 1 \text { session }\end{array}$ \\
\hline YDPC & 69 & $17(25 \%)$ \\
\hline Primary care providers & 51 & $12(23.5 \%)$ \\
\hline
\end{tabular}




\section{Compliance with Ethical Standards}

Funding: This study was funded by Indiana School of Medicine and Indiana University Health. Conflict of Interest: The authors declare that they have no conflict of interest.

This study was approved by the Indiana University Review Board. Informed consent was not obtained from the participants and their legal guardians for the following reasons: 1) the Indiana University IRB deemed the collection of program satisfaction and attendance as part of routine quality improvement measures rather than research 2) the group was conducted in a commonly accepted education setting involving normal nutrition and physical activity education practices 2) participation in the group did not put participants at a greater than minimal risk. 


\section{References}

1. Dabelea, D., Mayer-Davis, E. J., \& Saydah, S., et al. (2014). Prevalence of type 1 and type 2 diabetes among children and adolescents from 2001 to 2009. Journal of the American Medical Association, 311(17), 1778-1786. doi:10.1001/jama.2014.3201

2. Imperatore, G., Boyle, J. P., \& Thompson T. J., et al. (2012). Projections of type 1 and type 2 diabetes burden in the U.S. population aged $<20$ years through 2050: Dynamic modeling of incidence, mortality, and population growth. Diabetes Care, 35(12), 25152520. doi:10.2337/dc12-0669

3. The TODAY Study Group. (2007). Treatment options for type 2 diabetes in adolescents and youth: A study of the comparative efficacy of metformin alone or in combination with rosiglitazone or lifestyle intervention in adolescents with type 2 diabetes. Pediatric Diabetes, 8(2), 74-87. doi:10.1111/j.1399-5448.2007.00237.x

4. The Diabetes Prevention Program (DPP) Research Group. (2002). The Diabetes Prevention Program (DPP): Description of lifestyle intervention. Diabetes Care, 25(12), 2165-2171. 
5. Savoye, M., Caprio, S. \& Dziura, J.et al. (2014). Reversal of early abnormalities in glucose metabolism in obese youth: Results of an intensive lifestyle randomized control trial. Diabetes Care, 37(2), 317-324. doi:10.2337/dc13-1571

6. Golan, M. \& Crow, S. (2012). Targeting parents exclusively in the treatment of childhood obesity: Long-term results. Obesity, 12(2), 357-361. https://doi.org/10.1038/oby.2004.45

7. Bandura, A. (2005). Adolescent development from an agentic perspective. In T. Urdan \& F. Pajares (Eds.), Self-efficacy beliefs of adolescents (1-43). Greenwich, CT: Information Age Publishing.

8. Barlow, S.E. (2007). Expert committee recommendations regarding the prevention, assessment, and treatment of child and adolescent overweight and obesity: Summary report. Pediatrics, 120(4), S164-S192. doi:10.1542/peds.2007-2329C

9. Absetz, P., Valve, R., \& Oldenburg, B., et al. Type 2 diabetes prevention in the "real world": one-year results of the GOAL implementation trial. Diabetes Care, 30(10), 24652470. https://doi.org/10.2337/dc07-0171

10. Ackermann, R.T., Finch, E.A., Brizendine, E., Zhou, H., \& Marrero, D.G. (2008). Translating the Diabetes Prevention Program into the community. The DEPLOY pilot study. American Journal of Preventative Medicine, 35(4), 357-363. doi:10.1016/j.amepre.2008.06.035

11. Amundson, H.A., Butcher, M.K., \& Gohdes, D., et al. (2009). Translating the diabetes prevention program into practice in the general community: findings from the Montana Cardiovascular Disease and Diabetes Prevention Program. Diabetes Educator, 35(2), 209-10, 213-4, 216-20 passim. doi:10.1177/0145721709333269. 
12. Boltri, J.M., Davis-Smith, Y.M., Seale, J.P., Shellenberger, S., Okosun, I.S., \& Cornelius, M.E. (2008). Diabetes prevention in a faith-based setting: Results of translational research. Journal of Public Health Management \& Practice, 14(1), 29-32. doi:10.1097/01.PHH.0000303410.66485.91

13. Kanaya, A.M., Santoyo-Olsson, J., Gregorich, S., Grossman, M., Moore, T., \& Stewart, A.L. (2012) The Live Well, Be Well study: A community-based, translational lifestyle program to lower diabetes risk factors in ethnic minority and lower-socioeconomic status adults. American Journal of Public Health, 102(8), 1551-1558.

doi:10.2105/AJPH.2011.300456

14. Katula, J.A., Vitolins, M.Z., Rosenberger, E.L., et al. (2011). One-year results of a community-based translation of the Diabetes Prevention Program: Healthy-Living Partnerships to Prevent Diabetes (HELP PD) Project. Diabetes Care, 34(7), 1451-1457. doi: $10.2337 / \mathrm{dc} 10-2115$

15. McTigue, K.M., Conroy, M.B., Bigi, L., Murphy, C., \& McNeil, M. (2009). Weight loss through living well: Translating an effective lifestyle intervention into clinical practice. Diabetes Educator, 35(2), 199-204. doi:10.1177/0145721709332815 